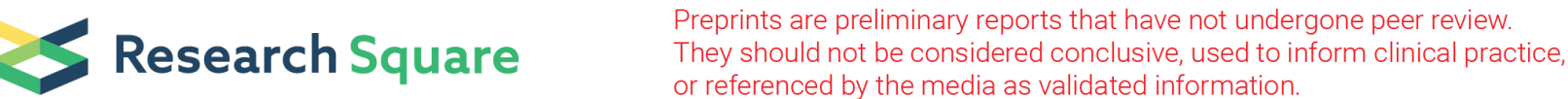

\section{The Role of Anterior Bladder Flap Neourethra (ABFN) in Early Urinary Continence after Laparoscopic Radical Prostatectomy The Anterior Bladder Flap Neourethra (ABFN) in RP}

\author{
Zhibin Xu \\ Taizhou People's Hospital \\ MaoMao Guo \\ Taizhou People's Hospital \\ Hao Bian \\ Taizhou People's Hospital \\ Zhenchi Li \\ Dalian Medical University \\ Chen Wang \\ Dalian Medical University \\ Zengxu Hong \\ Dalian Medical University \\ Jiangping Wang ( $\square$ mingzhujp@163.com ) \\ Taizhou People's Hospital
}

\section{Research Article}

Keywords: group, abfn, continence, control, urethral, laparoscopic, catheter, removal

Posted Date: August 5th, 2021

DOI: https://doi.org/10.21203/rs.3.rs-754448/v1

License: (c) (i) This work is licensed under a Creative Commons Attribution 4.0 International License. Read Full License 


\section{Abstract \\ Purpose}

To evaluate the impact of anterior bladder flap neourethra (ABFN) technique on early urinary continence after laparoscopic radical prostatectomy(RP).

\section{Materials and Methods}

Forty patients who underwent laparoscopic RP January 2019 to January 2021 were prospectively randomized into two groups: the ABFN group $(n=20)$ and the control group $(n=20)$. We compared continence rates and ICIQ-SF at $1 \mathrm{~d}, 30 \mathrm{~d}, 90 \mathrm{~d}$ and $180 \mathrm{~d}$ after catheter removal. In addition, the urethral pressure of two groups, the length and thickness of neourethra in the ABFN group were measured at one week after catheter removal.

\section{Results}

The ABFN group had marked improvement incontinence rates at $1 \mathrm{~d}, 30 \mathrm{~d}$ and $90 \mathrm{~d}$ after catheter removal vs the control group, while had the nearly same continence rate at $180 \mathrm{~d}$. ICIQ-SF scores of the ABFN group were lower than the control group. Maximal urethral pressure (MUP), functional urethral length (FUL) and functional urethral area (UFA) for the ABFN group has significantly improvement than the control group. MRI showed that the neourethral length of the ABFN group was 13.7-16.2 mm, the thickness was 3.6-5.2 $\mathrm{mm}$.

\section{Conclusions}

The ABFN technique markedly improved the early continence rate after laparoscopic RP.

\section{Background}

Early incontinence rates are as high as $26-93 \%$ in the first Mon and $19-85 \%$ in the third Mon after the standard radical prostatectomy (RP), dramatically impacting the patient's quality of life $\mathrm{e}^{1-4}$. Multiple surgical techniques aimed to improve post-RP early continence rate, for instance, methods with preservation of membranous urethra ${ }^{5,6}$, bladder neck ${ }^{7}$, Retzius space ${ }^{8}$, puboprostatic ligaments ${ }^{9}$, endopelvic fascia ${ }^{10}$, apical complex and lateral prostatic fascia ${ }^{11}$, and also techniques with the reconstruction of posterior reconstruction of rhabdomyosphincter ${ }^{12}$, periurethral suspension stitch ${ }^{13}$, anterior reconstruction ${ }^{14}$, anterior suspension and posterior reconstruction ${ }^{2}$, total anatomical reconstruction ${ }^{15}$. Although many patients had benefited from the above techniques, the effect is still uncertain and unreproducible ${ }^{16}$. For example, continence rates one month after RP with posterior 
reconstruction technique were $8.2 \%-82.6 \%^{16-19}$. In addition, some methods had a risk of positive surgical margin (PSM) $)^{20,21}$.

This study presented an improved surgical technique, anterior bladder flap neourethra (ABFN), to form a functional neourethra to achieve high continence rates in the early post-RP period.

\section{Materials And Methods}

\section{Study Population and Design}

We prospectively analyzed 40 patients (average age $73.1 \pm 3.2$ years) with localized prostate cancer from January 2019 to January 2021 and randomly divided them into two groups. Twenty patients in the control group underwent standard laparoscopic RP, and the other 20 patients underwent laparoscopic RP with ABFN. Age, BMI, PSA, prostate volume, IPSS score, biopsy Gleason score, clinical T stage, risk assessment CAPRA score, previous benign prostatic hyperplasia (BPH) surgery and neoadjuvant

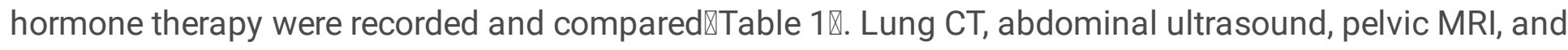
bone scan were conducted in all patients to exclude tumour metastasis. All patients were informed of the detailed surgical plan and possible risks before surgery and signed the informed consent. All methods were carried out in accordance with relevant guidelines and regulations. This study protocol was approved by the Research Ethics Committee of Jiangsu Taizhou People's Hospital.

\section{Surgical Technique}

All operations were performed by a team in transperitoneal access with five trocars distributed as a fan.

The control group: After standard laparoscopic prostatectomy, bladder outlet and urethra were directly anastomosed. The wide bladder outlet was narrowed by suturing the posterior wall longitudinally before anastomose.

The ABFN group: After standard laparoscopic prostatectomy, the bladder outlet was trimmed into a wide circle (Fig. 1A). An area approximately $15 \mathrm{~mm}$ wide was selected from the anterior bladder neck between 5 and 7 o'clock. A longitudinal incision of about $15 \mathrm{~mm}$ was made vertically on both sides to form a lingual bladder flap (Fig. 1B). The bladder outlet was closed using 3-0 barbed sutures in a continuous longitudinal pattern from 12 o'clock to the base of the lingual bladder flap (Fig. 1C). Longitudinal sutures were applied to both margins of the bladder flap, and a tubular neourethra was formed approximately 15 $\mathrm{mm}$ in length (Fig. 1C). The suture was inserted at a distance of $3 \mathrm{~mm}$ from the incision margin and was discharged from the mucosal edge of the bladder so that the mucosa and muscle layer of the bladder were tightly aligned. Neourethra was then anastomosed to the distal urethra (Fig. 1D). The detailed surgical method can refer to the supplementary video.

\section{Follow Up}


Concerning early urinary continence, follow up was at $1 \mathrm{~d}, 30 \mathrm{~d}, 90 \mathrm{~d}, 180 \mathrm{~d}$ after catheter removal in the outpatient department. Postoperative urinary control data were collected for all patients by January 2021. The patients were given the ICIQ-SF questionnaire. We defined Urinary continence as no pad or one safety pad. One week after catheter removal, we detected MUP, FUL and UFA of patients in the two groups, respectively. We performed an MRI examination to measure the distance, thickness and closure condition of the neourethra.

\section{Statistical Analysis}

Categorical variables were presented as percentages, while continuous variables were presented as mean and standard deviation or median and interquartile range. SPSS 25.0 software was used to perform independent samples $x^{2}$ test, $t$-test, or Wilcoxon rank-sum test of the data. The difference was statistically significant when a $p$-value is $<0.05$.

\section{Results}

\section{Patient and Tumor Characteristics}

There were no significant differences in age, BMI, PSA, prostate volume, IPSS score, biopsy Gleason score, clinical T stage, risk assessment CAPRA score, previous BPH surgery and neoadjuvant hormone therapy between the two groups, respectively (Table 1).

\section{Perioperative and Pathological Outcomes}

Operative times $(p=0.191)$ and estimated blood loss $(p=0.964)$ were similar in the control and ABFN groups. There were no anastomotic urine leakage and anastomotic stricture in the two groups. Pathological characteristics in terms of stage, Gleason score, PSM rates were similar between the two groups. PSM rates were $15.00 \%$ in both groups $(p=1.000)$ (Table 2$)$.

\section{Continence Date}

The ABFN group had marked improvement in continence rates at $1 \mathrm{~d}, 30 \mathrm{~d}$ and $90 \mathrm{~d}$ after catheter removal vs the control group ( $100 \%$ vs $5 \%, 100 \%$ vs $10 \%, p \otimes 0.001$ and $100 \%$ vs $60 \%, p=0.006)$, while had the nearly same continence rate at $180 \mathrm{~d}(100 \%$ vs $95 \%, p=1.000)$. The urinary continence rates of the ABFN group were $100 \%$ at different time spots (Table 3 ). Only two patients used a safety pad per day in 1-2 weeks after catheter removal. ICIQ-SF scores of the ABFN group were lower than the control group at $1 \mathrm{~d}$

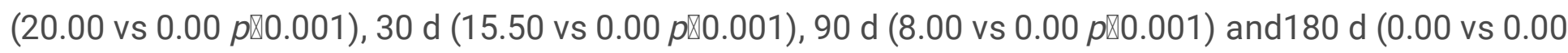
$p=0.038$ ) after catheter removal respectively (Table 4).

\section{Urethral Manometry Data}

At one week after catheter removal, MUP, FUL and UFA of the control group vs the ABFN group were $45.18 \pm 9.25 \mathrm{cmH}_{2} \mathrm{O}$ vs $61.56 \pm 20.31 \mathrm{cmH}_{2} \mathrm{O}(p=0.008), 32.06 \pm 5.06 \mathrm{~mm}$ vs $50.81 \pm 5.48 \mathrm{~mm}$ ( $\left.p \otimes 0.001\right)$ 
and $301.00 \pm 97.27 \mathrm{~mm} \times \mathrm{cmH}_{2} \mathrm{O}$ vs $684.44 \pm 202.73 \mathrm{~mm} \times \mathrm{cmH}_{2} \mathrm{O}(p \otimes 0.001)$ respectively (Table 5). FUL in the $A B F N$ group showed dual peak patterns, while the control group showed a single peak in urethral membrane pressure (Fig. 2A, 2B).

\section{MRI of ABFN}

The length and thickness of the neourethra were measured in the sagittal plane of the urethra MRI as 13.7-16.2 $\mathrm{mm}$ and 3.6-5.2 mm. The neourethra was narrow and long, with no urine filling (Fig. 3A, 3B), and the neourethral lumen in the cross-sectional plane was petal-shaped and tightly closed (Fig. $3 \mathrm{C}$ ).

\section{Other}

One patient in the ABFN group had difficulty urinating one day after removing the urethral catheter, which was relieved one week after retaining the urethral catheter. One patient in the control group had difficulty urinating two weeks after removing the urethral catheter and failed to place catheter. Urethroscopy revealed vesicourethral anastomotic stricture, which was relieved by giving two weekly dilations. All other patients in both groups voided freely and had no residual urine.

\section{Discussion}

The mechanism of incontinence in the early post-RP period (within three mons) is still unclear ${ }^{16}$. Still, many researchers have recognized the critical role of FUL in urinary continence ${ }^{16}$, and preserving bladder neck and apex urethra can maintain FUL and improve continence in the early post-RP period ${ }^{5,7,21}$. However, the prostate protruded at the apex. The bladder neck often squeezes the urethra and bladder neck and resulted in the inability to preserve these tissues with sufficient thickness and length. Meanwhile, maintaining the apex urethra and bladder neck has a risk of PSM at both ends of the prostate 20,21 .

More researchers also have recently recognized the function of FUL in RP is a significant cause of postoperative incontinence ${ }^{5,7,22}$. From the aspect of urodynamics, higher intraurethral pressure than intravesical pressure is essential, and FUL is the determining factor for urinary continence. According to the laws of fluid dynamics, urethral resistance and FUL are directly proportional to each other. Therefore, when FUL becomes shorter, it will reduce the ability of the urethra in continence. In addition, the urethra is an elastic tubular tissue that closes under abdominal pressure. When FUL is significantly shortened, the abdominal pressure on the urethra decreases, which reduces the ability of the urethra in continence.

ABFN forms a neourethra with specific length and thickness, which theoretically can increase FUL and improve urinary continence in the early postoperative period. However, ABFN conducted by Steiner in 1993 with a continence rate of only $55 \%$ in the third-month post-RP has no significant advantage over other current techniques ${ }^{23}$. Steiner found by cystography that the funnel-shaped bladder neck was filled with contrast medium in the early postoperative period. According to the laws of fluid dynamics, urethral resistance is inversely proportional to the urethral diameter. Therefore, we believe that Steiner cut the 
bladder outlet at 10 and 2 o'clock. As a result, the anterior bladder flap was too broad, resulting in a neourethra with an apparent funnel shape, which could not form a well-closed functional urethra. Unfortunately, since Steiner did not perform a functional analysis, such as urethral manometry, it was not possible to understand the functional status of the neourethra. In addition, since the surgery approach has been proved to be one of the factors affecting urinary continence ${ }^{24}$, the open surgery performed by Steiner may be one of the possible reasons for the low urinary continence rate.

Based on Steiner's work, we made a vertical incision in the anterior bladder wall at 5 and 7 o'clock of the bladder outlet and took a bladder flap about $15 \mathrm{~mm}$ wide and $15 \mathrm{~mm}$ long for curling and suturing to form a narrow, tubular neourethra. MRI showed narrow and long neourethras with sufficient thickness and good static closure shape. The functional urodynamic test revealed that the pressure of the neourethra formed the first peak of the pressure curve (Fig. 2B). The increased MUP and FUL significantly improved UFA in the ABFN group. As a result of the fact that ABFN had reconstructed FUL in morphology and function, all of the patients in the ABFN group achieved immediate urinary continence from the catheter removal.

ABFN does not require preservation of the structures and tissues surrounding the urethra and prostate, nor does it require deliberate protection of bladder neck or maximal urethra length. Thus, it avoids the PSM risk and the difficulty of the above preservation techniques and can be applied in all organ-confined prostate cancer cases. Furthermore, because the operation of the ABFN technique is simple and the diameter and length of the ABFN are relatively constant, ABFN does not increase the operation time and blood loss, which can be completed by any doctor who masters the standard laparoscopic technique. In addition, since ABFN is made of the bladder wall, its blood supply is abundant, and its edges heal well, avoiding neourethral luminal strictures and urinary fistulas.

Despite the prospective randomized study design, the limitations of this study included the small sample size, the lack of comparisons with other techniques, and the single-center setting.

\section{Conclusions}

In summary, ABFN showed a significantly better early continence rate than standard RP, an effective, safe and reproducible technique to improve the early continence rate. More definitive results would require further clinical studies with large numbers of cases.

\section{Declarations}

Funding $[$ No funding source was associated with this study.

Declarations of interest: There are no financial conflicts of interest to disclose.

Data availability: Not applicable. 


\section{Author's contributions:}

All authors whose names appear on the submission have contributed sufficiently to the scientific work and therefore share collective responsibility and accountability for the results. Jiangping Wang: Project development, data collection, data analysis, manuscript writing/editing. Zhibin Xu: Data collection, data analysis, manuscript writing. Maomao Guo: Data collection, data analysis, manuscript writing. Hao Bian: Data collection, manuscript writing. Zhenchi Li: Data collection, data analysis. Chen Wang: Data collection, data analysis. Zengxu Hong: Data collection, data analysis.

\section{References}

1. Ficarra, V. et al. Systematic review and meta-analysis of studies reporting urinary continence recovery after robot-assisted radical prostatectomy. Eur Urol, 62, 405-417 (2012).

2. Hurtes, X. et al. Anterior suspension combined with posterior reconstruction during robot-assisted laparoscopic prostatectomy improves early return of urinary continence: a prospective randomized multicentre trial. BJU Int, 110, 875-883 (2012).

3. Menon, M., Muhletaler, F., Campos, M. \& Peabody, J. O. Assessment of early continence after reconstruction of the periprostatic tissues in patients undergoing computer assisted (robotic) prostatectomy: results of a 2 group parallel randomized controlled trial. J Urol, 180, 1018-1023 (2008).

4. Sutherland, D. E. et al. Posterior rhabdosphincter reconstruction during robotic assisted radical prostatectomy: results from a phase II randomized clinical trial. J Urol, 185, 1262-1267 (2011).

5. Hamada, A., Razdan, S., Etafy, M. H., Fagin, R. \& Razdan, S. Early return of continence in patients undergoing robot-assisted laparoscopic prostatectomy using modified maximal urethral length preservation technique. J Endourol, 28, 930-938 (2014).

6. Choi, S. Y. et al. Does intraoperative frozen section really predict significant positive surgical margins after robot-assisted laparoscopic prostatectomy? A retrospective study. Asian J Androl, 23, 74-79 (2021).

7. Nyarangi-Dix, J. N., Radtke, J. P., Hadaschik, B., Pahernik, S. \& Hohenfellner, M. Impact of complete bladder neck preservation on urinary continence, quality of life and surgical margins after radical prostatectomy: a randomized, controlled, single blind trial. J Urol, 189, 891-898 (2013).

8. Umari, P. et al. Retzius-Sparing versus Standard Robot-Assisted Radical Prostatectomy: A Comparative Prospective Study of Nearly 500 Patients. J Urol, 205, 780-790 (2021).

9. Assem, A., Abou Youssif, T., Hamdy, S. M., Beltagy, A. M. \& Gozen, A. S. Role of sparing of puboprostatic ligaments on continence recovery after radical prostatectomy: a randomized controlled trial. Scand J Urol, 55, 22-26 (2021).

10. Siltari., A., Riikonen., J. \& Murtola., T. J. Preservation of Endopelvic Fascia: Effects on Postoperative Incontinence and Sexual Function - A Randomized Clinical Trial. J Sex Med, 18, 327-338 (2021). 
11. Covas Moschovas, M. et al. Modified Apical Dissection and Lateral Prostatic Fascia Preservation Improves Early Postoperative Functional Recovery in Robotic-assisted Laparoscopic Radical Prostatectomy: Results from a Propensity Score-matched Analysis. Eur Urol, 78, 875-884 (2020).

12. Jeong, C. W. et al. Effects of new 1-step posterior reconstruction method on recovery of continence after robot-assisted laparoscopic prostatectomy: results of a prospective, single-blind, parallel group, randomized, controlled trial. J Urol, 193, 935-942 (2015).

13. Patel, V. R., Coelho, R. F., Palmer, K. J. \& Rocco, B. Periurethral suspension stitch during robot-assisted laparoscopic radical prostatectomy: description of the technique and continence outcomes. Eur Urol, 56, 472-478 (2009).

14. Han, K. S. \& Kim, C. S. Effect of Pubovesical Complex Reconstruction During Robot-Assisted Laparoscopic Prostatectomy on the Recovery of Urinary Continence. J Laparoendosc Adv Surg Tech A, 25, 814-820 (2015).

15. Porpiglia, F. et al. Total Anatomical Reconstruction During Robot-assisted Radical Prostatectomy: Implications on Early Recovery of Urinary Continence. Eur Urol, 69, 485-495 (2016).

16. Vis, A. N. et al. Posterior, Anterior, and Periurethral Surgical Reconstruction of Urinary Continence Mechanisms in Robot-assisted Radical Prostatectomy: A Description and Video Compilation of Commonly Performed Surgical Techniques. Eur Urol, 76, 814-822 (2019).

17. Salazar, A. et al. Early continence after radical prostatectomy: A systematic review. Actas Urol Esp (Engl Ed), 43, 526-535 (2019).

18. Beattie, K. et al. A novel method of bladder neck imbrication to improve early urinary continence following robotic-assisted radical prostatectomy. J Robot Surg, 7, 193-199 (2013).

19. Wagner, J. R. \& Editorial comment. Long-term functional urinary out outcomes comparing single-vs double layer urethrovesical anastomosis: two year follow-up of a two-group parallel randomized controlled trial. Urology 76, 1107; author reply 1107-1108(2010).

20. Bellangino, M. et al. Systematic Review of Studies Reporting Positive Surgical Margins After Bladder Neck Sparing Radical Prostatectomy. Curr Urol Rep, 18, 99 (2017).

21. Heo, J. E., Lee, J. S., Goh, H. J., Jang, W. S. \& Choi, Y. D. Urethral realignment with maximal urethral length and bladder neck preservation in robot-assisted radical prostatectomy: Urinary continence recovery. PLoS One, 15, e0227744 (2020).

22. Schlomm, T. et al. Full functional-length urethral sphincter preservation during radical prostatectomy. Eur Urol, 60, 320-329 (2011).

23. Steiner., M. S. et al. Tubularized neourethra following radical retropubic prostatectomy. J Urol, 150, 407-410 (1993).

24. Park, B. et al. Comparison of oncological and functional outcomes of pure versus robotic-assisted laparoscopic radical prostatectomy performed by a single surgeon. Scand J Urol, 47, 10-18 (2013).

\section{Tables}


Table 1 Patient and tumor characteristics

\begin{tabular}{|c|c|c|c|}
\hline & Control $\triangle n=20 \otimes$ & $A B F N \rrbracket n=20 \rrbracket$ & $p$ value \\
\hline Age, yr & $73.35 \pm 2.91$ & $72.75 \pm 3.45$ & 0.555 \\
\hline $\mathrm{BMI}, \mathrm{kg} / \mathrm{m}^{2}$ & $23.93 \pm 2.55$ & $24.71 \pm 2.56$ & 0.343 \\
\hline $\mathrm{PSA}, \mathrm{ng} / \mathrm{ml}$ & $17.45 \pm 6.26$ & $16.80 \pm 5.40$ & 0.352 \\
\hline Prostate volume, $\mathrm{cm}^{3}$ & $56.65 \pm 12.01$ & $54.50 \rrbracket 48.25,58.75 \rrbracket$ & 0.745 \\
\hline IPSS score & $7.89 \pm 1.63$ & $7.66 \pm 1.69$ & 0.664 \\
\hline Biopsy Gleason score, $\mathrm{n}(\%) \rrbracket$ & & & 0.829 \\
\hline 6 & $2(10.00)$ & $1(5.00)$ & \\
\hline $7(4+3)$ & $12(60.00)$ & $12(60.00)$ & \\
\hline $7(3+4)$ & $4(20.00)$ & $6(30.00)$ & \\
\hline $8-10$ & $2(10.00)$ & $1(5.00)$ & \\
\hline Clinical T stage, $n(\%) \rrbracket$ & & & 1.000 \\
\hline T1 & $5(25.00)$ & $4(20.00)$ & \\
\hline $\mathrm{T} 2$ & $12(60.00)$ & $13(65.00)$ & \\
\hline T3 & $3(15.00)$ & $3(15.00)$ & \\
\hline Risk assessment CAPRA score, $\mathrm{n}(\%) \rrbracket$ & & & 0.780 \\
\hline Low & $2(10.00)$ & $1(5.00)$ & \\
\hline Intermediate & $13(65.00)$ & $15(75.00)$ & \\
\hline High & $5(25.00)$ & $4(20.00)$ & \\
\hline Previous BPH surgery, n (\%) & $2(10.00)$ & $3(15.00)$ & 1.000 \\
\hline Neoadjuvant hormone therapy, $\mathrm{n}(\%)$ & $4(20.00)$ & $4(20.00)$ & 1.000 \\
\hline
\end{tabular}

Table 2 Perioperative and pathological outcomes 


\begin{tabular}{|c|c|c|c|}
\hline & Control $₫ n=20 \rrbracket$ & $A B F N \otimes n=20 \otimes$ & $p$ value \\
\hline Operative time, mins & $157.25 \pm 38.73$ & $173.30 \pm 37.44$ & 0.191 \\
\hline Estimated blood loss, ml & $252.75 \pm 125.61$ & $251.00 \pm 121.25$ & 0.964 \\
\hline Anastomotic urine leakage, n (\%) & $0(0.00)$ & $0(0.00)$ & 1.000 \\
\hline Anastomotic stricture, n (\%) & $0(0.00)$ & $0(0.00)$ & 1.000 \\
\hline Positive surgical margin, $\mathrm{n}(\%)$ & $3(15.00)$ & $3(15.00)$ & 1.000 \\
\hline Pathological stage, $n(\%)$ : & & & 0.744 \\
\hline $\mathrm{T} 2$ & $13(65.00)$ & $12(60.00)$ & \\
\hline T3 & $7(35.00)$ & $8(40.00)$ & \\
\hline Pathological Gleason score, n (\%): & & & 1.000 \\
\hline 6 & $2(10.00)$ & $1(5.00)$ & \\
\hline $7(4+3)$ & $10(50.00)$ & $11(55.00)$ & \\
\hline $7(3+4)$ & $5(25.00)$ & $4(20.00)$ & \\
\hline 8-10 & $3(15.00)$ & $4(20.00)$ & \\
\hline
\end{tabular}

Table 3 Continence date at in different time spots

\begin{tabular}{|c|c|c|c|}
\hline \multirow[t]{2}{*}{ Days after catheter removal } & \multicolumn{2}{|c|}{ Postoperative continence $\ n$ (\%) } & \multirow[t]{2}{*}{$p$ value } \\
\hline & Control $\triangle n=20 \bigotimes$ & $A B F N \rrbracket n=20 \rrbracket$ & \\
\hline 1 & $1 \rrbracket 5.00 \bigotimes$ & $20 \rrbracket 100.00 \rrbracket$ & $\varangle 0.001$ \\
\hline 30 & $2 \otimes 10.00 \rrbracket$ & $20 \rrbracket 100.00 \rrbracket$ & $\nabla 0.001$ \\
\hline 90 & $12 \llbracket 60.00 \rrbracket$ & $20 \rrbracket 100.00 \rrbracket$ & 0.006 \\
\hline 180 & 19ه95.00ه & 20ه100.00》 & 1.000 \\
\hline
\end{tabular}

Table 4 ICIQ-SF scores

\begin{tabular}{|c|c|c|c|}
\hline \multirow[t]{2}{*}{ Days after catheter removal } & \multicolumn{2}{|l|}{ ICIQ-SF score } & \multirow[t]{2}{*}{$p$ value } \\
\hline & 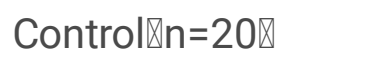 & $A B F N \rrbracket n=20 \otimes$ & \\
\hline 1 & $20.00(15.00,21.00)$ & $0.00(0.00,0.00)$ & $₫ 0.001$ \\
\hline 30 & $15.50(8.00,20.00)$ & $0.00(0.00,0.00)$ & $₫ 0.001$ \\
\hline 90 & $8.00(0.00,15.00)$ & $0.00(0.00,0.00)$ & $₫ 0.001$ \\
\hline 180 & $0.00(0.00,0.00)$ & $0.00(0.00,0.00)$ & 0.038 \\
\hline
\end{tabular}


Table 5 Urethral manometry data

\begin{tabular}{|c|c|c|c|}
\hline & Control $₫ n=20 \rrbracket$ & ABFN $\rrbracket n=20 \rrbracket$ & $p$ value \\
\hline MUP, $\mathrm{cmH}_{2} \mathrm{O}$ & $45.18 \pm 9.25$ & $61.56 \pm 20.31$ & 0.008 \\
\hline FUL, mm & $32.06 \pm 5.06$ & $50.81 \pm 5.48$ & $₫ 0.001$ \\
\hline JFA, $\mathrm{mm} \times \mathrm{cmH}_{2} \mathrm{O}$ & $301.00 \pm 97.27$ & $684.44 \pm 202.73$ & $\varangle 0.001$ \\
\hline
\end{tabular}

Figures 

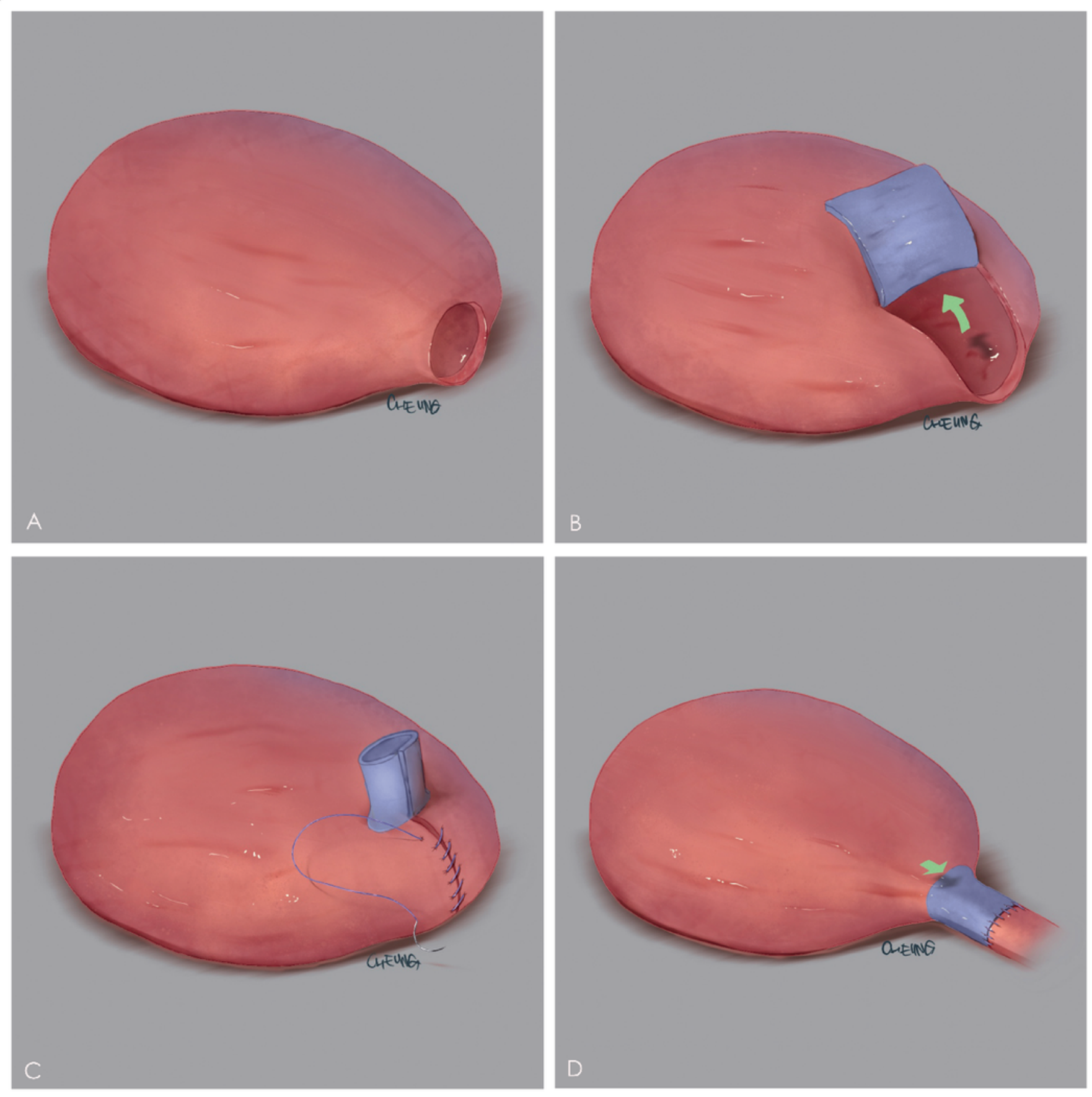

Figure 1. ABFN schematic diagram. (A) Morphology of bladder neck after prostatectomy. (B) Cuting the anterior bladder wall flap (blue) and turn it up in the direction of the green arrow. (C) Suturing bladder neck and forming ABFN (blue). (D) ABFN (blue) is pulled in the direction of the green arrow and anastomosed with the urethral end.

\section{Figure 1}

See image above for figure legend. 


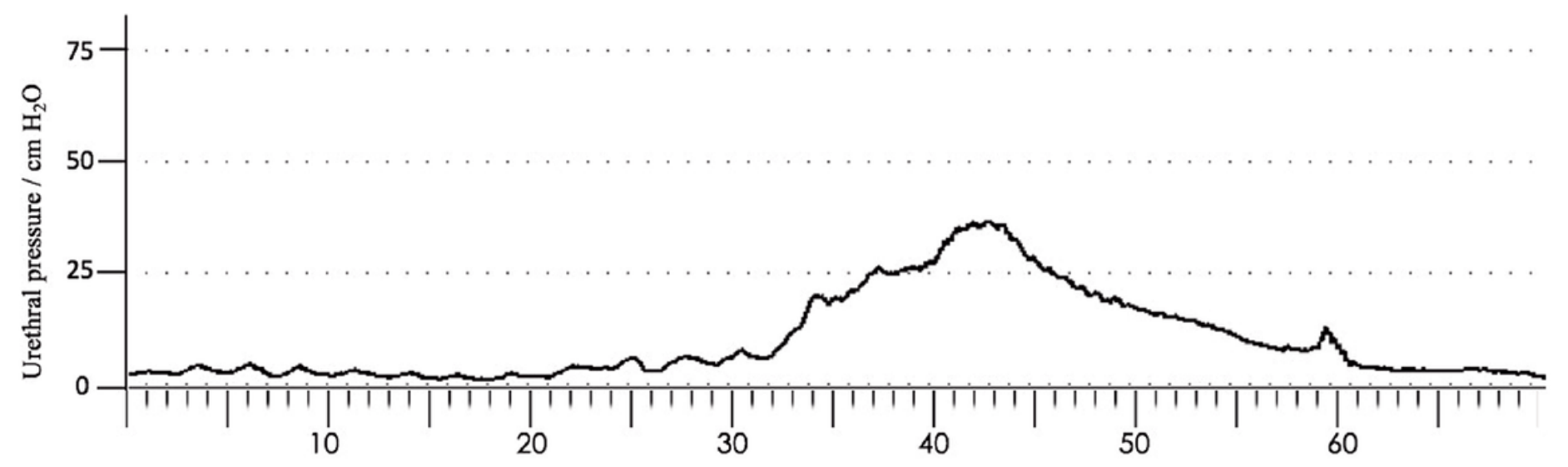

A

FUL / mm

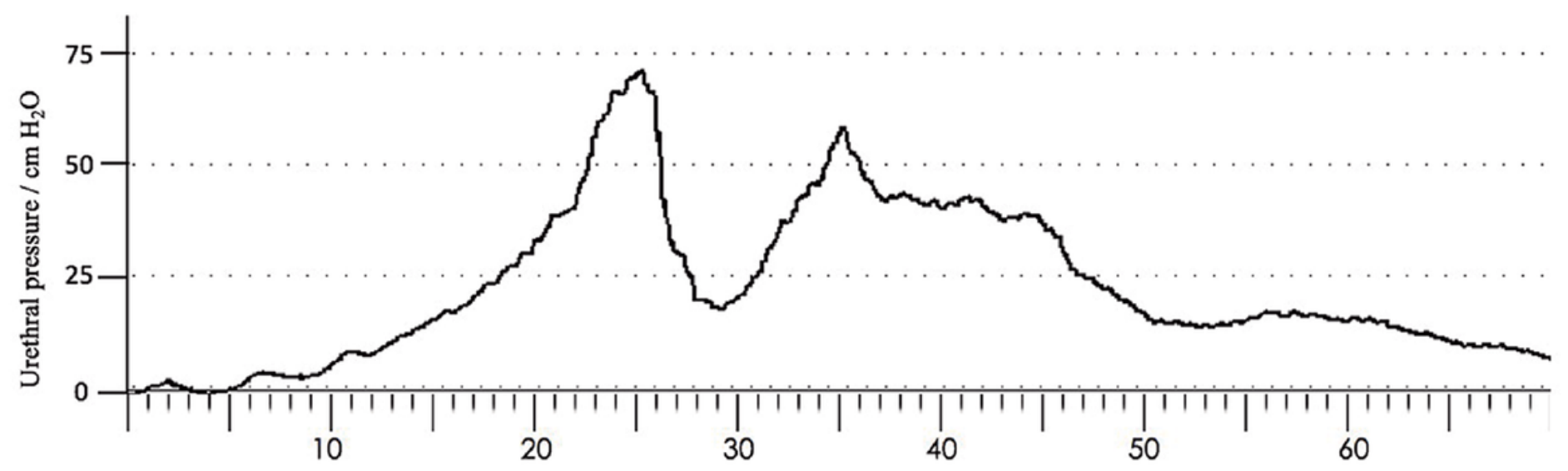

B

FUL / mm

Figure 2. Postoperative urethral pressure curve. (A) In the control group, the urethral pressure curve showed a singlepeak of membranous urethra. (B) In the ABFN group, the pressure curve showed two peaks of new urethra and membranous urethra.

\section{Figure 2}

See image above for figure legend. 

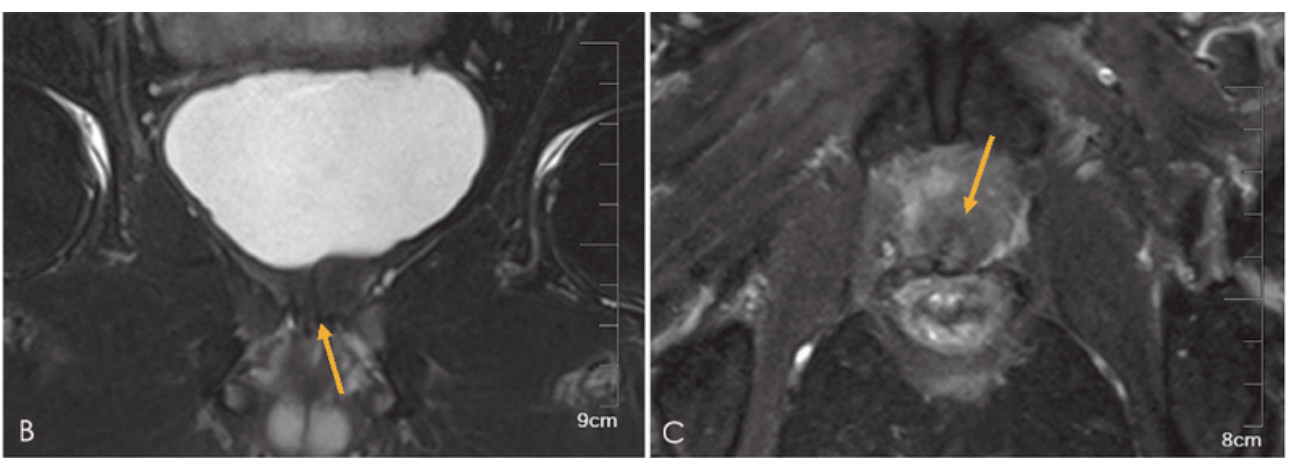

Figure 3. ABFN MRI image. (A) ABFN sagittal T1 image showed that the neourethra is narrow and long (yellow brackets). (B) ABFN frontal T2 image showed that the lumen of the neourethra the neourethra is narrow and long, with no urine filling in the lumen (yellow arrow). (C) ABFN frontal T2 image shows that the lumen of the neourethra is petal-shaped, closed tightly, and with no urine filling in the lumen (yellow arrow).

\section{Figure 3}

See image above for figure legend.

\section{Supplementary Files}

This is a list of supplementary files associated with this preprint. Click to download.

- SupplementaryVedio.mp4

- Supplementaryvideo.docx 